\title{
Methodological problems in the study of memory development: A critique of the Perlmutter and Myers experiment
}

\author{
DANIEL B. BERCH \\ University of New Mexico, Albuquerque, New Mexico 87131
}

\begin{abstract}
It is argued that in their report of a study of recognition memory in 2- to 4-year-olds, Perlmutter and Myers (1974): (a) arrive at an unwarranted conclusion regarding an age-related difference in "retention capacity," and (b) incorrectly attribute better performance on "new" than "old" items to a developmental lag in "proficiency." Suggestions are made regarding more appropriate methods for assessing developmental changes in retention.
\end{abstract}

Perlmutter and Myers (1974) recently found that 3to 4-year-olds performed significantly better on a recognition memory task than 2- to 3-year-olds. Using the unbiased index of retention, $\mathrm{d}^{\prime}$, they concluded that the "older children quite clearly showed greater retention capacity in this recognition memory task" (Perlmutter \& Myers, 1974, p. 450). (Author's emphasis.) On the basis of their procedure, however, this conclusion is obviously unwarranted. That is, since these investigators obtained only one data point for each subject, their procedure resulted in a confounding of retention capacity and degree of learning (acquisition). To make inferences about retention per se would require a measure of retention rate, i.e., the slope of a curve based on two or more data points that represent performance over varying retention intervals (RI) or lags (number of intervening items). One could then determine whether there is a difference in retention rates by examining the significance of the Age Level by RI interaction (Belmont \& Butterfield, 1969).

Perlmutter and Myers do state correctly that $\mathrm{d}^{\prime}$ represents the retention-based component of recognition performance as opposed to the criterion- or decision-based component. Yet this fact apparently led them to conclude that $d$ ' is a measure of "retention capacity." Strictly speaking, however, $\mathrm{d}^{\prime}$ is a measure of discriminability of the "old" and "new" items (Murdock, 1972). Furthermore, although the memory continuum does represent the strength or familiarity of memory "traces," the finding of a difference in trace strength at one retention interval (single data point) does not necessarily imply a difference in retention capacity. This is because most theories of memory employing a signal-detection model of the decision process, e.g., Wickelgren's (1970) multitrace strength theory, assume that each memory trace passes through successive phases consisting of acquisition, storage (retention), and retrieval.
This writer also finds fault with Perlmutter and Myers' interpretation of another set of findings from their experiment. The results indicated that whereas the 3- to 4-year-olds exhibited similar performance on old and new items (92\% and 93\% correct, respectively), the 2- to 3-year-olds were better at correctly recognizing new items ( $89 \%$ correct) than old items ( $72 \%$ correct). The authors concluded that, "Apparently, younger children are already extremely proficient at correctly rejecting stimuli that they have not previously seen in a recognition task, but not until a year later do they become equally proficient at correctly identifying previously observed stimuli" (Perlmutter \& Myers, 1974, p. 448). Subsequently, on the basis of the finding that the young subjects responded "yes" (old) less often overall (42\%) than the older subjects (49\%), Perlmutter and Myers speculated that younger children may adopt a more conservative criterion in making recognition judgments. However, they did not relate this evidence to their findings of better performance on new than old items for the younger subjects. Given the mean values (percentage correct) reported in the article, the present writer calculated a nonparametric index of response bias (criterion), RI (Frey \& Colliver, 1973). This analysis resulted in average RI values of -.27 for the younger subjects and -.01 for the older subjects. The value of -.01 is close enough to zero to indicate essentially a neutral response bias for the older subjects; this is reflected in their nearly equivalent performance on old and new items. But the RI value of -.27 for the younger subjects indicates a relatively strong tendency to say "no" (new) when uncertain. This finding alone can account for the better performance of younger subjects on new as compared to old items and thus obviates Perlmutter and Myers' differential "proficiency" explanation.

Perlmutter and Myers clearly indicated their awareness of the fact that there are substantial 
methodological problems in studying the development of recognition memory in very young children. Given that the present writer has raised serious questions regarding the validity of their procedure as well as their interpretations of the results, what can future researchers do to avoid similar pitfalls? Recently, Wickelgren (1975) suggested that "To study the rate of forgetting as a function of age, it is important to exclude age differences in acquisition, rehearsal, and retrieval" (p. 165). Toward this end, Wickelgren (1975) as well as Berch and Evans (1973) have advocated the use of the continuous recognition task (Shepard \& Teghtsoonian, 1961) to explore age differences in retention. Since there is no separate study phase in this type of task, the influence of age-related mnemonic strategies, such as spontaneous rehearsal, is greatly minimized (Brown, 1973); moreover, enough data points are provided to enable retention functions to be generated.

Using the continuous recognition procedure, Berch and Evans (1973) found no difference in the retention rates of 51/2. and 9-year-olds, although the initial acquisition level was substantially higher for the 9-year-olds. Similarly, Wickelgren (1975) found no differences in the retention rates of $91 / 2-, 21-$, and 68-year-olds on a continuous task but did find large differences in acquisition among these age groups. (Both of these studies used an unbiased index of sensitivity as the dependent variable.) These two experiments, then, have demonstrated no differences in retention per se among age groups spread out across most of the life span. Consequently, it is quite likely that an appropriately modified procedure for testing continuous recognition memory in very young children (1 to 4 years) would also reveal no developmental differences in retention rates within this age range. In any event, it is hoped that the present paper will stimulate further attempts at devising accurate techniques for studying memory development during the first few years of life. Meanwhile, given the present state of the art, investigators in this field would do well to adopt a relatively conservative criterion for concluding that there are in fact age-related differences in retention, per se.

\section{REFERENCES}

Belmont, J. M., \& Butterfield, E. C. The relations of shortterm memory to development and intelligence. In L. P. Lipsitt, \& H. W. Reese (Eds.) Advances in child development and behavior (Vol. 4). New York: Academic Press, 1969.

BERCH, D. B., \& Evans, R. C. Decision processes in children's recognition memory. Journal of Experimental Child Psychology, 1973, 16, 148-164.

BRown, A. L. Judgments of recency for long sequences of pictures: The absence of a developmental trend. Journal of Experimental Child Psychology, 1973, 15, 473-480.

Frey, P. W., \& Colliver, J. A. Sensitivity and responsivity measures for discrimination learning. Learning and Motivation, 1973, 4, 327-342.

Murdock,B. B., JR Short-term memory. In G. H. Bower (Ed.) The psychology of learning and motivation: Advances in research and theory (Vol. 5). New York: Academic Press, 1972.

Perlmutter, M., \& Myers, N. A. Recognition memory development in two- to four-year-olds. Developmental Psychology, 1974, 10, 447-450.

ShePaRd, R. N., \& Teghtsoonian, M. Retention of information under conditions approaching a steady state. Journal of Experimental Psychology, 1961, 62, 302-309.

WiCkelgren, W. A. Multitrace strength theory. In D. A. Norman (Ed.), Models of human memory. New York: Academic Press, 1970.

Wickelgren, W. A. Age and storage dynamics in continuous recognition memory. Developmental Psychology, 1975, 11, 165-169.

(Received for publication May 27, 1975.) 